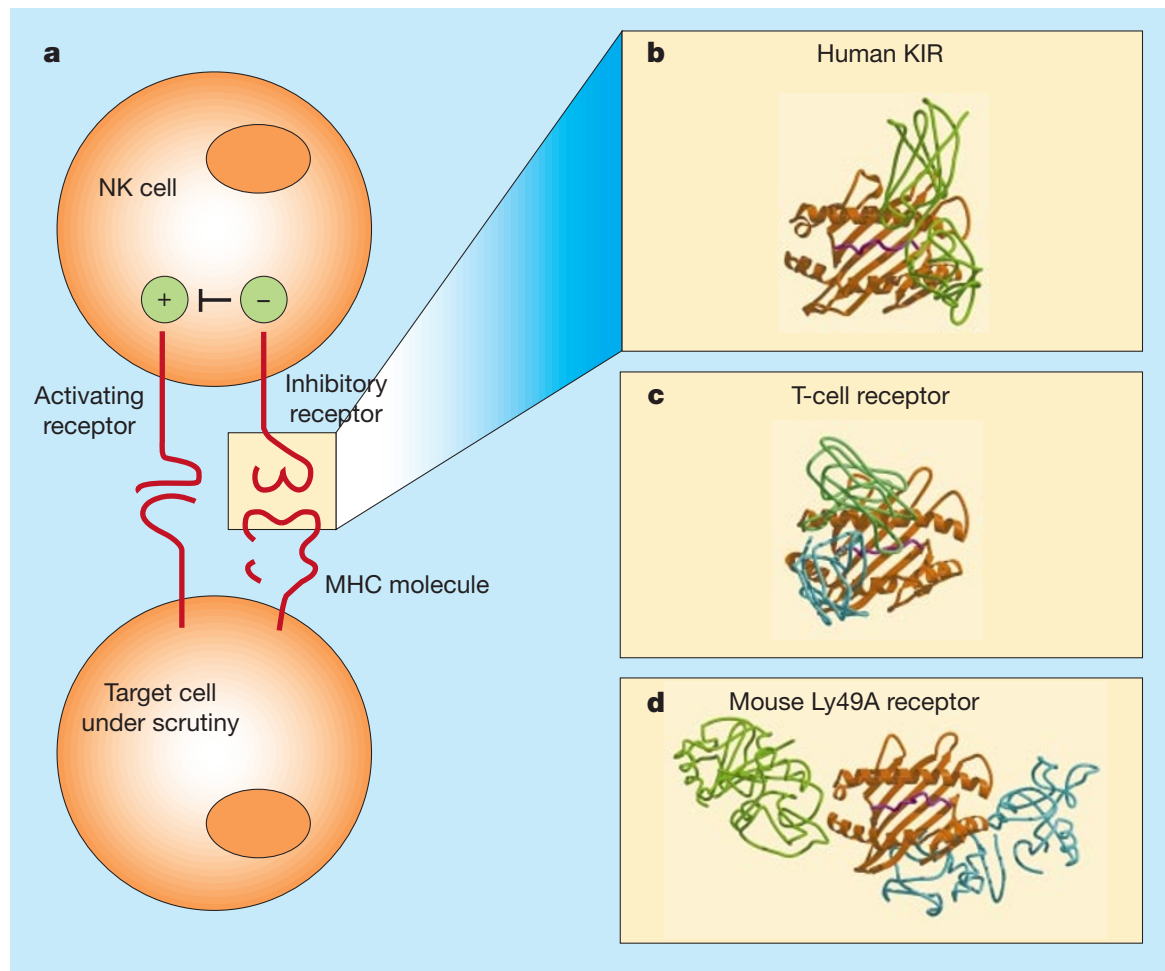

Figure 1 Life-saving liaisons. a, Natural killer (NK) cells can distinguish normal, healthy cells from aberrant cells in the body. Activating receptors on the NK cell recognize ligands on most normal cells. Signals from these receptors stimulate the NK cell to kill the target cell. But killing is stopped if killercell inhibitory receptors recognize adequate levels on the target cell of major histocompatibility complex (MHC) class I molecules. b, The 'footprint' (contact area) made by the human NK receptor KIR2DL2 on the antigen-binding groove of its MHC ligand, HLA-Cw3 (ref. 2), viewed from above. c, $d$, The footprints of a T-cell antigen receptor ${ }^{6}$ and of the murine NK receptor Ly49A (ref. 5) are shown for comparison. MHC is shown in red, MHC-bound peptide in purple, and the NK or T-cell receptors in green (and cyan). Note a second contact site for Ly49A beneath the antigen-binding groove. (b-d, Reproduced with permission from ref. 11.)

that differ between these KIRs is a partner in a critical hydrogen bond with an amino acid that differs between the relevant HLA-C subgroups.

The mouse and human receptor-ligand crystal structures indicate, unexpectedly, another binding site of the receptor to the MHC molecule, not identical in the two complexes. These sites may be involved in ligand-induced receptor aggregation ${ }^{2}$ or receptor interactions with ligands in the membrane of the NK cell itself ${ }^{5}$. But the biological significance of these interactions is yet to be established.

As ever, questions remain. Why have humans and mice developed different types of NK receptor, with analogous function but from completely different structural families? Might it be because the receptors need to recognize distinct parts of the MHC molecules (Fig. 1b, d)? And if so, why? Structures of other receptor-ligand pairs will be required before we can answer these questions. Genomics studies indicate that these evolutionarily recent KIR proteins show considerable diversity, even at residues that do not contact MHC molecules ${ }^{10}$ (P. Parham, personal communication). This diversity is evolving rapidly, even by comparison to the

MHC genes ${ }^{10}$. Might peptides or other KIR ligands from infectious agents represent the evolutionary driving force here? Finally, NK cells sometimes carry variants of KIR proteins that activate killing when they recognize MHC ligands. The function of the activating receptors is unknown - will their footprints on the MHC molecule provide the answer?

Klas Kärre is at the Microbiology and Tumor Biology Center, Karolinska Institute, Box 280, 17177 Stockholm, Sweden.

e-mail:klas.karre@mtc.ki.se

Gunter Schneider is in the Department of Medical Biochemistry and Biophysics, Karolinska Institute, Box 280, 17177 Stockholm, Sweden.

1. Kärre, K., Ljunggren, H. G., Piontek, G. \& Kiessling, R. Nature 319, 675-678 (1986).

2. Boyington, J. C., Motyka, S. A., Schuck, P., Brooks, A. G. \& Sun, P. D. Nature 405, 537-543 (2000).

3. Moretta, A. et al. Annu. Rev. Immunol. 14, 619-648 (1996).

4. Fan, Q. R. et al. Nature 389, 96-100 (1997).

5. Tormo, J., Natarajan, K., Margulies, D. H. \& Mariuzza, R. A. Nature 402, 623-631 (2000).

6. Garboczi, D. N. et al. Nature 384, 134-141 (1996).

7. Rajagopalan, S. \& Long, E. O. J. Exp. Med. 185, 1523-1528 (1997).

8. Ruggeri, L. et al. Transplantation 94, 333-339 (1999).

9. Mandelboim, O. et al. J. Exp. Med. 184, 913-922 (1996).

10. Wilson, M. J. et al. Proc. Natl Acad. Sci. USA 97, 4778-4783 (2000).

11.http://red.niaid.nih.gov/mhc-complexes.html
Daedalus

\section{Air currents}

Many reactors circulate their molten sodium coolant by an electromagnetic pump. A current passes through the molten metal at right angles to an applied magnetic field, and the motor effect impels the sodium at right angles to both. Daedalus reckons it would work with insulating fluids too. For a voltage applied across an insulator shifts its electrons transiently, as the insulator becomes polarized. Remove the voltage, and they would move back again. In a steady magnetic field, these two brief opposite 'displacement currents' would exert a push and then a cancelling pull on the dielectric. But reverse the magnetic field in the interval, and the dielectric would feel two pushes in the same direction - a true motor effect.

So, says Daedalus, put an insulator in a.c. electric and magnetic fields at right angles, reversing at the same frequency and the right mutual phase, and it will feel a cumulative force. At first he hoped that the whole thing could be driven as a resonant circuit, with the insulator as the dielectric of its capacitor, and the inductor providing the magnetic field; but the phasing comes out wrong. The two fields will have to be created and phased by special circuitry.

The obvious working fluid for the new pump is air. Fans, propellers, blowers and jet engines are all noisy, complicated devices. A simple silent air-pump with no moving parts would be widely welcomed. For maximum thrust, it should work at the highest feasible frequency - many megahertz if possible. Daedalus's first product will be a little cooling blower for computers and electronic gadgets. But he soon hopes to scale it up. Displacementcurrent pumping could make all sorts of blowers, compressors, air-conditioners and fans blissfully silent and reliable.

His ultimate goal is a displacementcurrent aircraft engine. The entire craft would have to be designed around this radical new source of thrust. Its fields would enclose as large a volume of air as possible, so that even a gentle induced flow moved a lot of air. An electromagnetic helicopter with vertical downflow might fill the bill. The strength and direction of thrust could be altered at electronic speed, giving the craft a wonderful agility in the air. And its total silence would be welcomed both by the crew and the longsuffering aerophobic public. David Jones

The Further Inventions of Daedalus is published by Oxford University Press. 